\title{
All Aboard: The Industrial Technology Department Head's View of Time-on-Task by Distance Education Faculty
}

\author{
Stanley L. Lightner \\ University of Nebraska at Kearney \\ Kearney, NE, USA
}

lightnersl@unk.edu

\author{
W.C. Johnson \\ Mississippi State University \\ Mississippi State, MS, USA
}

\section{Executive Summary}

Many prior studies have addressed student and faculty attitudes toward Distance Education. This study adds to the body of knowledge by considering the administrator's view within the context of Industrial Technology departments. The attitudes of department heads need to be explored since department heads make budgetary and time allocation decisions that affect the entire departmental regimen, and thus have a direct effect on the success of Distance Education efforts.

Distance education as a delivery mode is gaining widespread use in Industrial Technology. Many professionals are encouraged to embrace the new methodology while at the same time, issues such as physical setting, time-on-task, ownership of intellectual property, preparation time, faculty productivity, and traditional vs. nontraditional contact hours have not been conclusively resolved by administrators. The attitudes of Industrial Technology Department Heads are at the vanguard of bringing clarity, continuity and a smooth transition to distance education. Industrial Technology faculty and students will find this article useful in creating a shared vision and development of a sanguine relationship within the Industrial Technology family.

Major points include: 1) description of the attitude of Industrial Technology department heads toward distance education; 2) changes portended by the attitudes of department heads; 3) promotion and tenure issues; 4) commitment of resources; 5) expectations and professionalism; and 6) paradigm shifts.

Overall, department heads seem to view distance education as valuable as traditional time-and-placebound education. However, there appears to be a sizeable minority who question the value of distance education. This is most apparent in questions dealing with the cost of distance education, the value of student projects completed via distance education, and the amount of time faculty must spend on the computer. Over one-third of the department heads studied do not think that there should be any difference in the productivity measures used for traditional and distance education faculty. Given the amount of time necessary to develop distance education courses, this does not bode well for junior faculty working toward promotion and tenure while teaching via distance.

Material published as part of this journal, either on-line or in print, is copyrighted by the publisher of the Journal of Information Technology Education. Permission to make digital or paper copy of part or all of these works for personal or classroom use is granted without fee provided that the copies are not made or distributed for profit or commercial advantage AND that copies 1) bear this notice in full and 2) give the full citation on the first page. It is permissible to abstract these works so long as credit is given. To copy in all other cases or to republish or to post on a server or to redistribute to lists requires specific permission and payment of a fee. Contact Editor@ JITE.org to request redistribution permission.
Therefore, the movement of Industrial Technology faculty into distance education needs to be carefully planned, and methodically introduced to ensure professionalism through proper consideration of time, compensation, resource allocation, faculty evaluation, and promotion/tenure issues. The attitudes of department heads are of great value in ensuring the proper mesh of expectations, professional responsibility, allocation of 
resources, scheduling, and securing institutional commitment.

\section{Introduction}

Higher education institutions are escalating their efforts to meet the growing demand for expanded educational opportunities. More and more students are demanding course delivery schemes that are not time and place specific. The emergence of distance education as a course delivery mode is quite evident in our culture. Distance education advocates argue that its rapid expansion is part of the technological revolution on campuses, and institutions that are not "with the program" will be left behind. Others see distance education as a cornucopia for survival in times of low enrollment and budget restraints.

Higher education administrators enthusiastically herald the technological revolution that is sweeping American campuses. Department chairs put pressure on faculty to use technology in their teaching, and to participate in distance education. Concomitantly, little thought is given to such issues as research/publishing demands, teaching load, promotion/tenure, or time-on-task (Higher Education Research Institute, 1999). Rockwell, Schaeur, Fritz, and Marx (1999) identified five obstacles to teaching from a distance (1) time requirements, (2) time taken from research, (3) training requirements, (4) developing effective technology skills, (5) assistance with on-line course design and delivery. At the heart of the above obstacles lie considerations that form the lifeblood of survival in academia - time for research and publishing. The prudent faculty member would be wise to focus on the components of the academic regimen that ensures inclusion and longevity in the system. Teaching, research and service form the trilogy of credible activity that generally guides promotion and tenure in American academia. The most vulnerable to abuse are the junior faculty who must, in addition to showing yearly progress, make the mselves available for additional assignments, thus diminishing their ability to do "scholarly" work. Current research directing higher education toward practical solutions to the distance education mindset seems, at the moment, limited. Ehrmann (1997) suggested that current research has failed to ask the right questions when comparing traditional teaching to distance education. He further proposes that until a full accounting is made of the innumerable and complex variables linked to distance education, decisions will continue to be flawed. The Institute for Higher Education Policy (2000) identified four complex variables that must be addressed in quality distance education programs (1) encouragement to use technical assistance in course development, (2) assistance in transition from traditional to distance learning, (3) available support, and (4) assistance and training.

Deciding to embrace distance education may bring accolades from department chairs; however, it is also important to note the paradigm shift when getting the job done is actually considered. Hanna (1999) suggested that the technologies of distance education have changed, but attitudes remain the same.

Recent distance education literature has both recommended and described the kinds of paradigm changes needed for the successful implementation of distance education (Hanna, 1999; Higher Education Research Institute, 1999; Institute for Higher Education Policy, 2002; McKenzie, 2000). Schifter (2000) went further to identify two critical parts of the distance education infrastructure that seem contravening, at first glance, but make prefect sense upon closer examination - the art of teaching, on the part of the teacher, and - the art of learning, on the part of the student. The art of teaching involves both motivation to change and efficacy. There is less motivation for change among senior-level faculty than junior-level faculty, (Rockwell, Schauer, Fritz, and Mark, 2000). Senior- level faculty is more inclined to use their traditional style of teaching than to embrace newer ones. They generally feel uncomfortable with the new technology. Thusly, they are reluctant to accept assignments as distance learning instructors. This reluctance can inevitably lead to the denial of distance participants to the more experienced senior-level faculty. According to Rahman (2001), when senior-level faculty opt out of the distance education option, departmental leaders allow the denial of an invaluable asset to students. Students who participate in distance education classes tend to be independent critical thinkers who desire an open and 
challenging learning environment. They want to take ownership of their learning and actively participate. As Stake and Hoffman (2001) put it, these are the attributes senior-level faculties indicate they want in prospective students. To address the needs and concerns of this group of students, Hurst (2001) identified four things that must change: (1) mentoring, (2) office hours (3) testing, and (4) evaluation. These changes foretell the need to closely examine the monastery of the traditional place-bound academic environment.

Faculty motivation to participate in distance education was studied by Betts (1998). The findings of his study indicated that while administrators believe extrinsic motivation (credit toward Promotion and Tenure, merit pay) was a major factor in choosing to teach by distance learning; faculty indicated intrinsic factors (intellectual challenge) as major motivators. From another perspective, Passmore (2000) reviewed distance education literature, covering a decade, and found that senior-level faculty tended to be intrinsically motivated while junior-level faculty tended to be extrinsically motivated. This research corroborates what Betts found two years earlier, and seems to indicate that junior level faculty are more accepting of new modes of teaching, but must also pay attention to promotion and tenure concerns. At the same time, senior-level faculty has already achieved success in academia and is possibly inclined to adhere to their tried and proven practices. In many cases, this does not include the embrace of distance education. Kassop (2003) presents an enthusiastic perspective of the quality benefits of senior-level faculty's participation in distance education. After reviewing the attitudes of faculty in the New Jersey Community College Consortium, he surmised the mechanics of moving from a face-to-face mode to an online mode actually energized many of the instructors. Perhaps there is a subtle message for the academic administrator who wants to get more faculty involved in distance education. An energized faculty would, possibly, be more accepting of the larger time commitment, and virtual physical arrangements (neither traditional instructor-led classrooms nor traditional office hours). Perhaps the administrator's ability to energize faculty, more than attention to extrinsic motivators is to the greater good.

The mindset of the department chair plays a major role in faculty self-reporting, and general feeling of success. If the addition of distance education classes is seen as "just another routine scheduling task" a serious error in professional judgment has occurred. The entire equation for the amount of time committed to the task of successfully launching distance education programs needs to change. McKenzie (2000) indicated that more time is spent in preparation for distance courses than for traditional courses. Additionally, distance faculty interacted with students from 13 to 15 hours more per week than teachers in traditional programs.

Finding the proper balance of competent faculty, significant rewards and proper time-on-task, while keeping an eye toward promotion and tenure issues should provide fodder for much further research. The part played by the attitudes of department heads toward distance education needs to be explored since they make budgetary and time allocation decisions that affect the entire departmental regimen. As industrial technology departments attempt to meet the growing demands for distance education courses, the attitudes of department heads needs to be assessed and potential barriers identified.

\section{Study Design}

The purpose of this study was to ascertain the attitudes of industrial technology department heads toward time-on-task by distance education faculty. Within the context of this study, Distance Education was defined as course work delivered via the Internet or by interactive video. The information gathered by this study was designed to be used to better utilize time, personnel, learning strategies, and promote teacher efficacy.

The National Association of Industrial Technology (NAIT) supplied a list of all Deans, Chairs, and Heads in the 2002 Baccalaureate Directory and their e-mail addresses, if available. There were 293 names in the list of which 37 did not have an e-mail address. All of the remaining 256 administrators on 
the list were e-mailed, of which 38 e-mails were returned as undeliverable. An additional nine individuals replied to the e-mail but indicated they were no longer an administrator, or lacked the information necessary to give a reasoned response to the survey. Thus, there remained a population of 209 for the survey. Total number of respondents was 46 out of 209 for a $22 \%$ response rate.

\section{Survey Results}

The overwhelming majority, or 37 of $46(80.4 \%)$ of those responding to the survey, were departme ntal heads or chairs. The other respondents included two Coordinators of Graduate Studies, or 4.3\%; one Associate Dean, or $2.2 \%$; one Director of External Programs, or 2.2\%; two Program Coordinators, or 4.3\%; one Associate Professor, or 2.2\%; one person who indicated "other"; and one individual who did not identify his or her position, or $2.2 \%$. (See Table 1.)

The participants were also polled as to their level of experience with education. They were asked: "What experience(s) do you have with distance education?" with the following possible answers and directed to "check all that apply." Twenty-one people indicated they had taught courses by distance education. Distance Education instructors had been supervised by 28 of the respondents. Twelve of the respondents had taken courses designed to prepare them to teach by distance education and 16 had taken courses delivered by distance education. (See Table 2.)

In an attempt to exert as little influence on the responses as possible, the survey's open-ended question was asked at the beginning of the survey rather than the end of the survey. The respondents were asked: "What has had the greatest influence on the formation of your attitude toward time-on-task in distance education?" There were twenty-seven answers to this question, of which 20 could be placed in four categories. Six of those responding felt the need for more or the

\begin{tabular}{|c|c|}
\hline Title & $\begin{array}{c}\text { Number } \\
\text { (Percentage) }\end{array}$ \\
\hline $\begin{array}{c}\text { Department } \\
\text { Head/Chair }\end{array}$ & $37(80.4 \%)$ \\
\hline $\begin{array}{c}\text { Coordinator of } \\
\text { Graduate Studies }\end{array}$ & $2(4.3 \%)$ \\
\hline Associate Dean & $1(2.2 \%)$ \\
\hline $\begin{array}{c}\text { Director of } \\
\text { External Programs }\end{array}$ & $1(2.2 \%)$ \\
\hline Program Coordinator & $2(4.3 \%)$ \\
\hline Associate Professor & $1(2.2 \%)$ \\
\hline Other & $1(2.2 \%)$ \\
\hline Not identified & $1(2.2 \%)$ \\
\hline
\end{tabular}

Table 1: Responses by Position

\begin{tabular}{|c|c|}
\hline Taught via distance & 21 \\
\hline $\begin{array}{c}\text { Supervised those who } \\
\text { Taught via distance }\end{array}$ & 28 \\
\hline $\begin{array}{c}\text { Prepared to teach via } \\
\text { Distance }\end{array}$ & 12 \\
\hline $\begin{array}{c}\text { Taken courses via dis- } \\
\text { tance }\end{array}$ & 16 \\
\hline
\end{tabular}

Table 2: Responses by Experiences with Distance Education lack of enough preparation time had the greatest influence on their attitude toward time-on-task in distance education. The ability to reach students, who typically would be unable to participate in higher education, or similar statements, was cited by eight people as having the greatest influence on their attitude toward time-on-task in distance education. Three individuals referred to equipment concerns, as did three others who voiced reservations about their lack of experience in distance education as having the greatest influence on their attitude toward time-on-task in distance education.

Not all respondents answered all the questions, thus some have less than a total of 46 responses. The number of respondents for each question is indicated at the end of the question. The responses are indicated after each possible answer by number of responses and the percentage these responses represent for each answer. The mean and standard deviation (S) for each question is also indicated with strongly agree assigned a value of five, agree a value of four, undecided a value of three, disagree a value of two, and strongly disagree a value of one. (See Table 3.) 
Table 3: Results

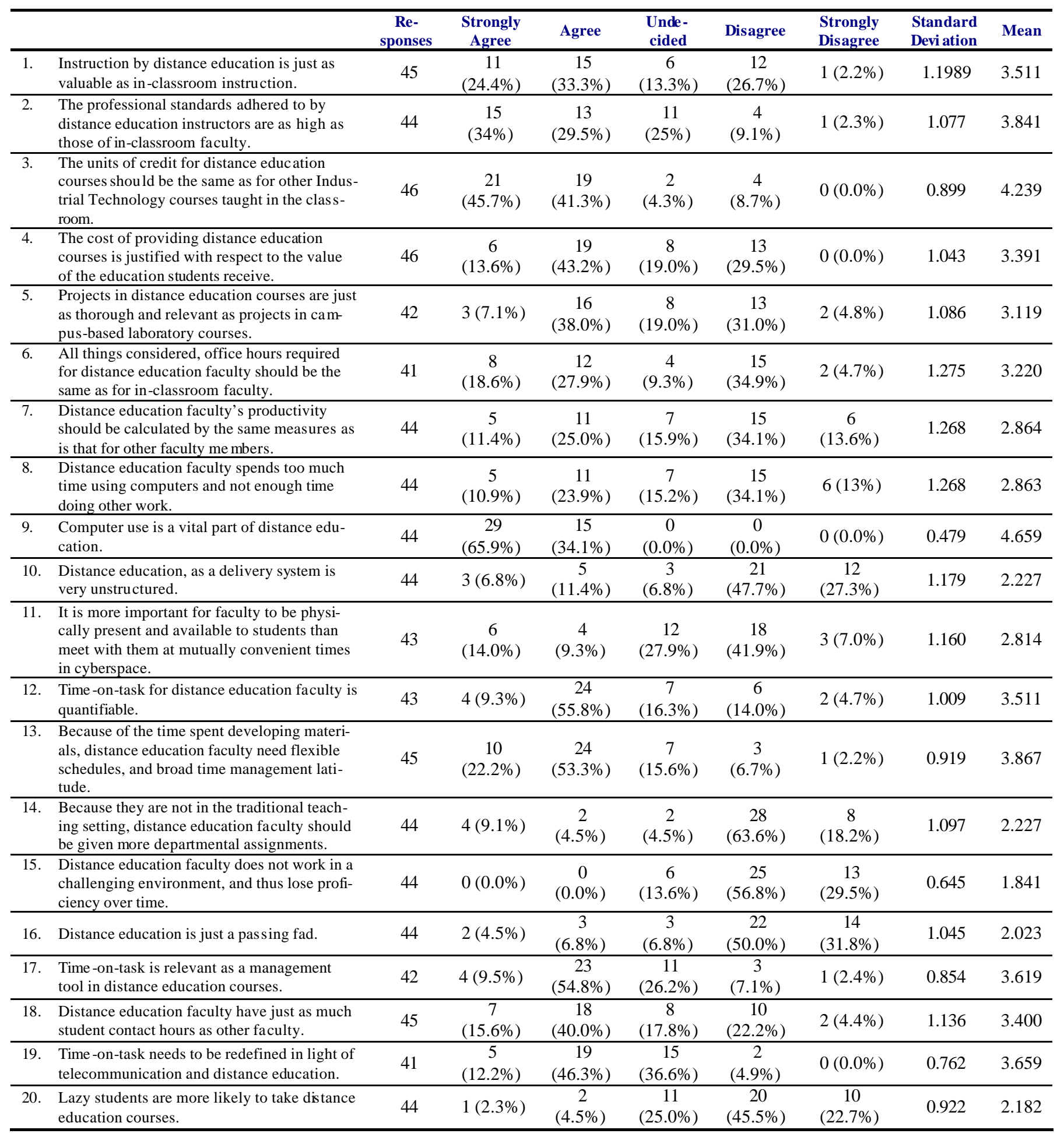

\section{Discussion of Results}

Overall the department heads seem to view distance education as valuable as traditional time and place bound education. However, some of the answers indicate there is a sizeable minority of department heads who question the value of distance education. This is indicated by the roughly $30 \%$, or more, of the respondents to questions 4,5 , and 8 who indicated the cost of distance education is too high, the student projects are not as relevant, and the faculty spend too much time using computers. Question 8 could 
also be interpreted as indicating the department heads do not see using the computer as "real work", but more like playing a video game. Additionally, it could possibly indicate a lack of knowledge of technology, or a lack of exposure to teacher educators at both the graduate and undergraduate level who did not use technology in their teaching (Bosh \& Cardinale, 1993; Glenn, 1993; Rodrigues, 1997). Motamedi (2000), in studying teacher education graduates from Mississippi State University, found that pre-service teachers who were taught by teacher educators who integrated technology into their teaching were more likely to be more comfortable with, and use technology when they became teachers. Carrying this logic one step further, we can generally surmise that teachers who become department heads would generally display similar behavior, and view distance education and its attending technologies as invaluable in the educational setting of the $21^{\text {st }}$ century.

Question 9, having the lowest Standard Deviation, seems to indicate a general agreement by the participating department heads in this study on the universality of the computer in the distance education delivery method. Additional clustering around the Mean possibly shows general acceptance of distance education as a course delivery method, and an interest in maintaining program quality. While this seems to be true, some department heads seem cognitively aligned with paradigms of traditional face-to-faceteaching methods in industrial technology programs, which could adversely effect the evaluations of those teaching via distance.

Of particular note is the striking difference of opinions generated by question 7 , regarding the calculation of faculty productivity. Over one-third of the department heads do not think there should be any difference in the productivity measures used for traditional faculty and distance education faculty. Given the amount of time necessary to develop distance education courses, this does not bode well for junior faculty working toward promotion and tenure and teaching via distance. In striking contrast to this attitude, are the answers to questions 12, 17 and 19. It seems the overwhelming majority of department heads believe time-on-task for distance faculty is quantifiable, is relevant as a management tool, and needs to be redefined for distance faculty. It would be interesting to see the results of a study that measured the difference in promotion and tenure rates for junior faculty who teach by distance and those who are in a more traditional setting.

The respondents to the survey appear to indicate:

- Synchronous and asynchronous contacts are as important as physical presence among faculty and students.

- Time management is a critical area in distance education instruction.

- Scheduling of classes and departmental assignments must be taken into consideration for distance education faculty.

- Paradigms that support promotion/tenure of distance education faculty are needed.

- Time-on-task is a critical consideration in the departmental regimen.

\section{Conclusion}

The primary purpose of this study was to ascertain the attitudes of Industrial Technology department heads toward time-on-task by distance education faculty. Due to the small number of responses, findings of this research may not be generalized to the general population. Nonetheless, this study provides insights into department head thinking and may serve as a research prototype for further review of issues associated with distance education as a course delivery mode.

Respondents in this study appear to value synchronous and asynchronous contacts as much as face-toface contact between teacher and student. This notion is given buoyancy in that the literature indicates 
that the typical distance education student is an independent learner who enjoys the challenge of finding solutions to problems, and appreciates the art of stimulating inquiry.

While time management is viewed by the findings of this research as critical to successful implementation of distance education, it is interesting to note that because of the promotion and tenure issue, juniorlevel faculty have more pressure on them than their senior-level counterparts. Perception is another aspect of time-on-task that, while sometimes subtle, sets the stage for other events in the departmental regimen. Passmore's (2000) review of ten years of distance education research found that academic administrators think distance education faculty, junior-level or senior-level, tend to be motivated by extrinsic factors, concomitantly, faculty indicated intrinsic factors as motivators. Critical dialog between administrators and faculty could help to create a common definition of expectations.

Distance education has ushered in a need for new ways of thinking about the physical dynamics of the education workplace. New ways of thinking about traditional office hours, class schedules, student contact hours, and scholarly activities are possibly needed in order to morph into formats that more clearly value the individual and epitomizes quality to cohorts and to the casual observer.

\section{References}

Barone, C. A. (2001). Condition for transformation infrastructure is not the issue. Educause Review, 36 (3), 41-47.

Betts, K. S. (1998). Factors influencing faculty participation in distance education in post-secondary education in the United States; An institutional study (Doctoral Dissertation, the George Washington University) Dissertation Abstracts International: UMI.

Bosh, K. A. \& Cardinale, L. (1993). Pre-service teachers' perceptions of computer use during a field experience. Journal of Computing in Teacher Education, 10(1), 23-27.

Chizmar, D. \& Williams, D. B. (2001). What do faculty want? Educause. 24 (1), 24.

Ehrmann, S. (1997). Asking the right questions: What does research tell us about technology and higher learning? In Engines of inquiry: A practical guide for using technology to teach American culture. Retrieved August 24,2002, from http://www.georgetown.edu/crossroads/guide/ehrmann.html

Glenn, A. D. (1993). Teacher education: One dean's perspective and forecast on the state of technology and teacher prep. Electronic Learning, 12 (5), 18-19.

Hanna, D. E. (1999). Higher education in area of digital competition: Choices and challenges. Madison, WI: Atwood Publishing.

Higher Education Research Institute. (1999, September). Faculty survey. Retrieved August 24, 2002, from http://www.gseis.ucla.edu/heri/press_faculty.htm

Hurst, F. (2001) Administrators and faculty resist culture, values, and traditions germane to higher education (The death of distance learning). Educause Quarterly, 24 (3), 59.

Institute for Higher Education Policy. (2000, August). Quality on the line: Benchmarks for success in internet-based distance education. Washington, DC. Retrieved March 29, 2002, from http://www.nea.org/he/abouthe/quality .pdf

Kassop, M. (2003). Ten ways online education matches, or surpasses, face-to-face learning. The Technology Source. Retrieved June 3, 2003 from http://ts.mivu.org/default.asp?show=article\&id=1059

McKenzie, B. K. (2000, Fall). Needs, concerns and practices of online instructors. Online Journal of Distance Education Administration, 3 (1). State University of West Georgia, Distance Education Center. Retrieved April 3, 2003 from http://www.westga.edu/ distance/ojdla/fall33/mckenzie33.html

Motamedi, V. (2000). Preparation in the use of technology among teacher education majors at Mississippi State University (Doctoral Dissertation, Mississippi State University) Dissertation Abstracts International: UMI.

Passmore, D. (2000). Impediments to adoption of web-based course delivery among university faculty. ALN Magazine, 4 (2). Retrieved May 15, 2003, from http://www.aln.org/publications/magazine/v4n2/passmore.asp

Rahman, M. (2001). Faculty recruitment strategies for online programs. The Online Journal of Distance of Distance Learning Administration. IV (IV). Retrieved May, 5, 2003, from http://www.westga.edu/ distance/ojdla/winter44/rahman44.html 
Rockwell, K., Schaeur, J., Fritz, S. M. \& Marx, D. B. (1999, Winter). Incentives and obstacles influencing higher education faculty and administrators to teach via distance. Online Journal of Distance Education Learning Administration, 2 (4). Accessed September 29, 2002, from http://www.westga.edu/ distance/rockwell24.html

Rodrigues, W. E. (1997). Raising the bar, lowering the barriers. Vital Speeches of the Day. 63 (2), 375-379.

Schifter C. (2000). Faculty participation in asynchronous learning networks: A case study of motivating and inhibiting factors. Journal of Asynchronous Learning Networks, 5 (2). Accessed May 15, 2003, from http://www.aln.org/publications/jaln/v4n1/v4n1_schifter.asp

Stakes, J., \& Hoffman, F. (2001). Changes in student social attitudes, activism, and personal confidence in higher education: The role of women's studies. American Research Journal, 38 (2), 411-436.

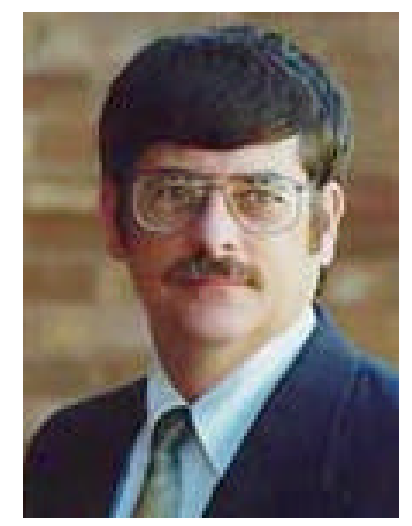

\section{Biographies}

Dr. Stan Lightner is an assistant professor in the largest NAIT accredited Industrial Distribution program, located at the University of Nebraska at Kearney. More information is available at their web site at http://www.unk.edu/acad/itec/idhome.html His background includes industrial experience in the processing of materials via machining, welding, assembly, forging, and casting. Dr. Lightner earned his bachelor and master's degrees from Northeastern State University in Tahlequah, Oklahoma and his doctorate from Oklahoma State University. His primary research interest is in the improvement of industrial technology curriculum.

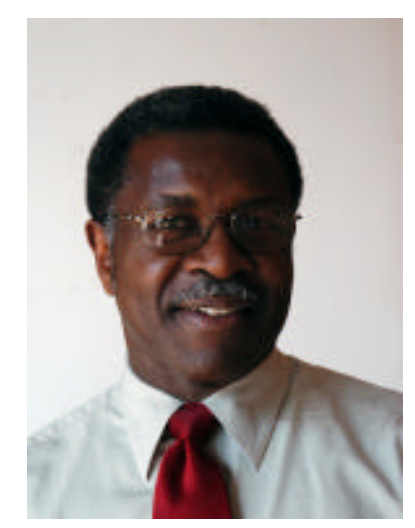

Dr. W. C. Johnson is an associate professor in the Instructional Systems, Leadership and Workforce Development department at Mississippi State University. He received the B. S. degree in industrial arts from Alcorn State University, the M. S. degree in industrial education from Indiana State University, and the Ed.D. in industrial education/vocational administration from The University of Minnesota. He currently teaches instructional technology and vocational licensure and certification courses through the interactive video/ distance education format. His main research interests are distance education and administration and supervision of vocational and technical education. He has recently published in The Journal of Industrial Technology, and The American Technical Education Association Journal. 